\title{
Effects of herbicide mixtures on freshwater microalgae with the potential effect of a safener ${ }^{\star}$
}

\author{
Ousama Chamsi ${ }^{1}$, Eric Pinelli ${ }^{1}$, Bruno Faucon ${ }^{\dagger}$, Annie Perrault ${ }^{1}$, Laurent Lacroix ${ }^{2}$, \\ José-Miguel Sánchez-Pérez ${ }^{1}$, and Jean-Yves Charcosset ${ }^{1, *}$ \\ ${ }^{1}$ EcoLab, Université de Toulouse, CNRS, INPT, UPS, Toulouse, France \\ 2 Laboratoire de Biologie Moléculaire Eucaryote (LBME), UMR 5099 CNRS/Université Paul Sabatier, 118 route de Narbonne, \\ 31062 Toulouse Cedex 9, France
}

Received: 30 May 2018; Accepted: 15 January 2019

\begin{abstract}
Freshwater microalgae are primary producers and cosmopolitan species subjected to the effects of herbicides. In this work, the in vitro algal growth inhibitory effects of 11 agrochemicals ( 9 herbicides, 1 metabolite, and 1 safener) were quantified. Chemical compounds were applied singly and in specific mixtures. Three species were used in axenic condition: the green alga Desmodesmus subspicatus (Chodat), the diatoms Nitzschia palea (Kützing) W. Smith and Navicula pelliculosa (Kützing) Hilse. When exposed to single compounds, $N$. palea and $N$. pelliculosa were only sensitive to atrazine/desethylatrazine and the safener benoxacor (BE), respectively. D. subspicatus was equally sensitive to four herbicides including atrazine and its metabolite and significantly more sensitive to iodosulfuron-methyl-sodium (IODO). The mixture of these five compounds induced a significantly higher growth inhibition of about 1.5-fold than IODO alone, which could be attributed to the four other herbicides. The mixture of all compounds was twofold less toxic than IODO on D. subspicatus. A halogen atom is present in IODO as in the herbicides to which the safener BE - known to induce glutathione- $S$-transferases - is associated in agrochemical preparations. We then showed that IODO was less toxic when combined with non-toxic concentrations of BE. These results indicated that the toxicity of the most active herbicide studied was decreased by a non-herbicide compound present in agrochemical formulations of other herbicides. These results suggest the importance to take into account the chemistry and the mechanisms of action for each compound in a risk assessment approach of a complex mixture.
\end{abstract}

Keywords: agrochemical mixtures / benoxacor / diatom / green alga / growth inhibition assay / microbial ecotoxicology

\section{Introduction}

Among many compounds of anthropogenic origin, pesticides that are used to enhance agricultural yields are extensively used and spread in all environmental compartments (Silva et al., 2015). All these compounds are finally found in surface water and in groundwater (Devault et al., 2007; Carvalho et al., 2014; Baker et al., 2016). In addition, short pulses of high concentrations of pesticides can be detected in water (Gilliom, 2007), especially after heavy rain and during high river flow (Spalding and Snow, 1989;

\footnotetext{
‡ This paper is dedicated to the memory of our late colleague, Dr. Bruno Faucon, who recently passed away.

${ }^{\dagger}$ Deceased.

*Corresponding author: jean-yves . charcosset@univ-tlse3.fr
}

Schulz, 2001; Polard et al., 2011). Such studies also show that aquatic organisms are exposed to cocktails of several compounds, in particular, agrochemicals.

These anthropogenic chemicals can induce growth inhibition, genotoxicity, and teratogenicity in microalgae (Debenest et al., 2008, 2010; Sjollema et al., 2014). Moreover, genotoxicity and/or endocrine alterations have been reported in zooplanktonic organisms, invertebrates, and fishes (Hanazato, 2001; Cavas, 2011; Peschke et al., 2014). Pesticides can also alter biological interactions between organisms at individual, population, and community level ( Hanazato, 2001; Debenest et al., 2009; Gonzalez-Rey et al., 2015). Numerous direct and indirect trophic cascade effects have been reported in aquatic communities (Fleeger et al., 2003). Such toxicants are known to modify the behaviour and the competition among both producer and consumer communities of aquatic organisms (Weis et al., 2001; Gonzalez-Rey et al., 2015). 
Because green algae and diatoms are primary producers at the beginning of freshwater trophic chains, pesticides may disrupt the balance of the whole ecosystem if microalgae communities are impacted (Ghosh and Gaur, 1998; Stoemer and Smol, 1999; Debenest et al., 2008). As they share with plants a chlorophyll $a / b$ photosynthetic system, green algae are at first concerned by herbicides that target photosystem II (Debenest et al., 2010). Besides, other herbicides that target amino acids synthesis (Duke and Dayan, 2011), fatty acids/lipids synthesis (Carder and Hoagland, 1998; Böger, 2003), and carotenoid biosynthesis (Lee et al., 1997; Ferhatoglu and Barrett, 2006) along with less targeted metabolisms are also expected to affect the growth of microalgae. Moreover, non-target effects are often described, in particular, when high concentrations of xenobiotics are recorded (Chèvre et al., 2006). Besides, the safeners that have no herbicidal activity on their own can display an effect on non-target organisms (Abu-Qare and Duncan, 2002). Hence, agrochemical mixtures that are contaminating surface and groundwater can modify the development of microalgae through various mechanisms.

Based on diatom populations and communities structures, several diatomic indices help to evaluate the effect of both chemical and physical environmental parameters on the ecosystem health taking into account that their results are specific of each method (Rimet et al., 2005). These indices also include the effects of xenobiotics on targeted and non-targeted organisms but do not allow evaluating their specific effects because the variation of the environment becomes a confounding effect. In mesocosms, community ecology has been shown to predict the effect of agrochemical mixtures on biodiversity and ecosystem services when the number of organisms and pollutants are strictly limited (Halstead et al., 2014). Alternatively, direct measurement of the effect of xenobiotics on microalgae can help to evaluate their effect on the aquatic ecosystems. In this line, species-sensitive distribution analysis has been developed to deal with multiple species toxicity (Posthuma et al., 2002). However, due to the lack of detailed information on the bioavailability and the mechanism(s) of action of each compound along with the chemical interaction(s) between them, it is difficult to predict the effects of various mixtures that slightly differ in their composition. Hence, a component-interaction analysis is required in which the assessment of the effects of xenobiotics mixtures one by one along with testing each compound singly is performed in microplates. As the reported methods are time-consuming because the microplate wells become red one by one (e.g., Nagai et al. (2013)), an efficient method would help to process large amounts of samples.

In order to assess the effect of xenobiotics in surface and groundwater, we have developed a method that allows processing simultaneously 12 microplates within a short run with high sensitivity. We then assessed the effect of nine herbicides of various mechanisms of action, one herbicide metabolite and one safener widely used in the south-west of France. These compounds were tested singly and in specific mixtures on the green alga Desmodesmus subspicatus (Chodat), and the diatoms Nitzschia palea (Kützing) W. Smith and Navicula pelliculosa (Kützing) Hilse that are widespread freshwater microalgae.

\section{Materials and methods}

\subsection{Chemicals}

The agrochemicals were selected after a survey of the herbicide formulations currently used in a riparian area of the river Garonne (Monbéqui) located in the south-west of France. The nine herbicides, the metabolite of atrazine (DEA) and the safener benoxacor (BE), which increases tolerance of maize to $S$-metolachlor and atrazine (Online Tab. 1), were purchased from Sigma-Aldrich (St Louis, MO 63103, USA, St Quentin-Fallavier, France). Aclonifen (ACLO), atrazine (ATRA), fenoxaprop- $P$-ethyl (FENO), isoxaflutole (ISOX), desethylatrazine and benoxacor were dissolved in acetone. Clomazone (CLOM), imazamox (IMAZ), iodosulfuronmethyl-sodium (IODO), metazachlor (META) and $S$-metolachlor (SMET) were dissolved in sterilized milli-Q water (Millipore, Billerica, MA).

For each molecule, concentration inducing $50 \%$ growth inhibition of various green microalgae and diatoms were retrieved from Tomlin (2009) to determine a reference concentration value (RCV). In order to take account of (i) the difference in sensitivity between species and (ii) an additive, subtractive or synergistic effect of the compounds in mixtures, we applied to the three tested microalgae a nominal concentration range that encompassed $0.1-10$-fold the RCV value set as 1 . Within this range, a geometric sequence of nine concentrations was centred on the RCV (Tab. 1). This range of concentration determined for each compound was used when the compounds were tested both singly and in mixtures. Then, $\mathrm{IC}_{50}$ of the compounds tested singly on the three microalgae were determined in molar concentration (Tab. 3). For the green alga, the fraction of RCV was used to compare the mixtures with the most active compound (IODO) and to compare the effect of the combination of the safener BE and IODO with that of IODO.

\subsection{Microalgae cultures}

According to the European Organisation for Economic Co-operation and Development (OECD), we tested 11 chemicals on D. subspicatus and N. pelliculosa as they are suitable for the testing of chemicals in growth inhibition test (Anonymous, 2011). We also included the widespread freshwater diatom N. palea (Larras et al., 2013; Abdullin and Bagmet, 2015; Moisset et al., 2015). The strain SAG 86.81 of D. subspicatus was obtained from the Culture Collection of Algae at Göttingen University. $N$. pelliculosa CCMP 543 and N. palea CPCC 160 were supplied by the Culture Collection of Massachusetts University and the Canadian Phycological Culture Center of the University of Waterloo, respectively. The COMBO medium (Kilham et al., 1998) adapted to fit the nutrient requirements of periphytic and epilithic algae was stored at $4 \pm 0.5^{\circ} \mathrm{C}$. The strains were maintained in agitated flasks (90 rpm, $25 \mathrm{~mm}$ orbital path) under the following conditions: $12 \mathrm{~h} / 12 \mathrm{~h}$ (day/night) at $20 \pm 0.5^{\circ} \mathrm{C}, 70 \%$ air relative humidity, PAR $120-150 \mu \mathrm{mol} \cdot \mathrm{m}^{-2} \cdot \mathrm{s}^{-1}$ provided by sodium-vapour lamps (Philips $600 \mathrm{~W}$, Eindhoven, The Netherlands). 
Table 1. The concentration range of each tested agrochemical. The reference concentration value (RCV) was determined from the literature and referred to as 1.00 for each compound. The concentrations of each agrochemical corresponding to the fraction of the RCV are indicated.

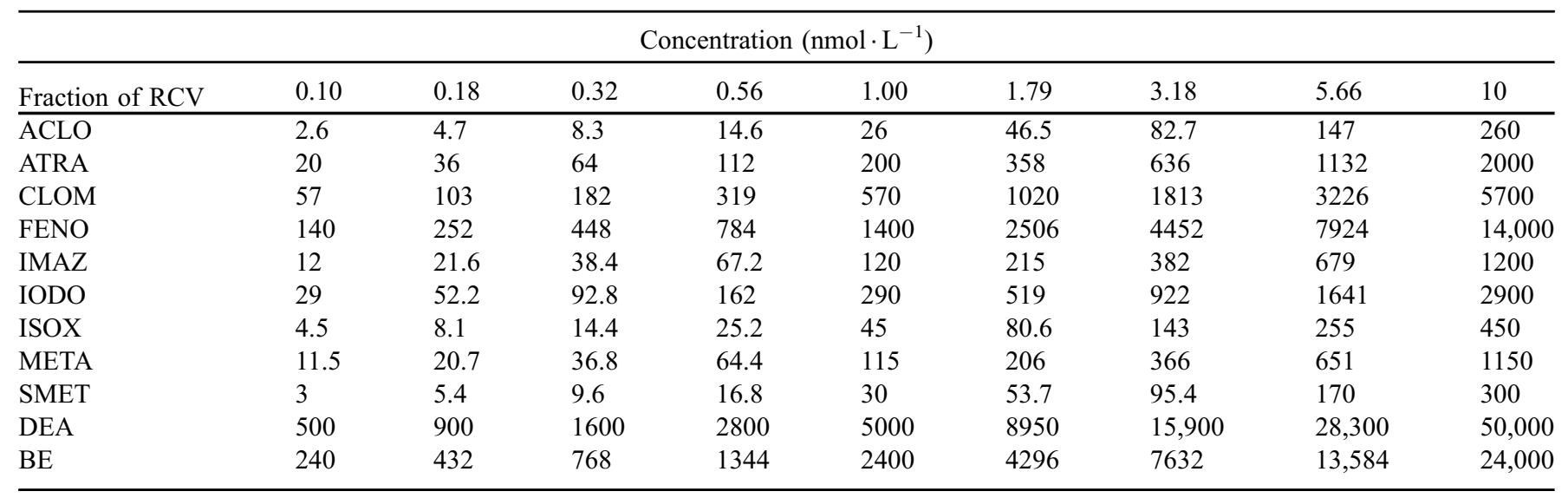

Table 2. The mixtures and combinations of the tested agrochemicals. In the mixtures, the concentration range of each tested agrochemical was used ( $c f$. Tab. 1). In IODO + BE combinations, the concentration range of IODO was applied ( $c f$. Tab. 1), whereas the BE concentration was kept constant (the corresponding fraction of RCV determined from the dose-response curve of this compound is indicated).

\begin{tabular}{ll}
\hline $\begin{array}{l}\text { Mixture/ } \\
\text { combination }\end{array}$ & Components \\
\hline MixAll & The 11 agrochemicals listed in Table 1 \\
MixDs & ATRA + DEA + FENO + META + IODO \\
MixDsw/oIODO & ATRA + DEA + FENO + META \\
IODO+BE1 & IODO + BE $\left(2400 \mathrm{nmol} \cdot \mathrm{L}^{-1} ; 1.00\right.$-fold RCV) \\
IODO+BE2 & IODO + BE $\left(7632 \mathrm{nmol} \cdot \mathrm{L}^{-1} ; 3.18\right.$-fold RCV) \\
\hline
\end{tabular}

\subsection{Algal growth inhibition assay}

In order to set the measurement conditions of growth, we first determined the absorption 3D spectra for the COMBO medium alone and each microalga grown in this medium using a Fluorolog-3 spectrofluorimeter (Horiba Scientific, Fukuoka, Japan) (Online Fig. 1). We then selected the suitable excitation and emission wavelengths that corresponded to the lowest possible autofluorescence of the COMBO medium and the highest possible autofluorescence of the microalgae in order to quantify the growth of each living microalga species. Agreeing with the spectra obtained with the Fluorolog-3, we used a Typhoon 9410 (GE Healthcare Life Sciences, Pittsburgh, PA) with the $488 \mathrm{~nm}$ excitation of the argon laser ( $10 \mu \mathrm{m}$ pixel size) and the $670 \mathrm{~nm}$ bandpass emission red filter 670BP30 to measure the fluorescence intensity in each well of a 96-well microplate for the growth inhibition assay. These wavelengths are in accordance with those used by Nagai et al. (2013), who reported that fluorescence intensity measured by flow cytometry and cell density counts of each of the three microalgae used in our study were highly correlated. After the scan of one microplate, the ImageQuant software (GE Healthcare) allowed to map the digital information to the appropriate pixel location and to quantify the fluorescence intensity. Twelve microplates of one experiment could be scanned in one 15 min run.

We first established the relationship between fluorescence intensity and cell density of the three microalgae in microplates. At time 0 , triplicate $500 \mathrm{ml}$ agitated flasks containing $100 \mathrm{ml}$ of COMBO medium were seeded with an inoculum of 5000-50,000 cells $\mathrm{ml}^{-1}$ taken from an exponential phase culture. After seeding, $200 \mu \mathrm{l}$ of each flask was transferred in a well of a 96-well polystyrene transparent microplate with low evaporation lid (Falcon ${ }^{\circledR}$ cat. \# 35-3072, BD Biosciences, San Jose, CA). Microplates were incubated as indicated in Section 2.2 in non-agitated condition. Fluorescence intensity was then measured with the Typhoon 9410 and cells were counted with Malassez counting chamber on $200 \mu \mathrm{l}$ aliquots transferred from the flasks to wells of new microplates. After 48 and $96 \mathrm{~h}$, fluorescence and cell density were quantified directly in the non-agitated microplates. The mean of the COMBO medium autofluorescence intensity $\left(40 \times 10^{6}\right.$ a.u. (arbitrary unit)) was subtracted from the fluorescence measured in the wells of the non-agitated microplates.

Eleven compounds were first tested singly and in a mixture (MixAll) on the three algae. In this mixture and the two others (Tab. 2), each agrochemical compound was tested at the concentration range indicated in Table 1. When tested singly, six compounds displayed an activity, of which five on $D$. subspicatus that include the two that were also active on N. palea. Two mixtures were then tested on the three species: (i) MixDs that comprises the compounds that displayed an effect on this species; (ii) MixDs without IODO (MixDsw/ oIODO), the compound that displayed the strongest effect. Then we tested the effect of the safener BE at two different concentrations that did not inhibit or stimulate the green alga growth. In these IODO $+\mathrm{BE}$ combinations, the $\mathrm{BE}$ concentration (BE1 and BE2) indicated in Table 2 is constant over the concentration range determined for IODO (Tab. 1). To set the $\mathrm{BE}$ concentration, we first took into account that the highest concentration of $\mathrm{BE}$ was toxic ( $40 \%$ growth inhibition) on D. subspicatus. Hence, we fixed $\mathrm{BE}$ at constant concentration in order (i) to use non-toxic BE concentrations (BE1: 1.00-fold RCV and BE2: 3.18-fold RCV that caused 0 and 4\% growth inhibition, respectively) and (ii) to mimic different field 

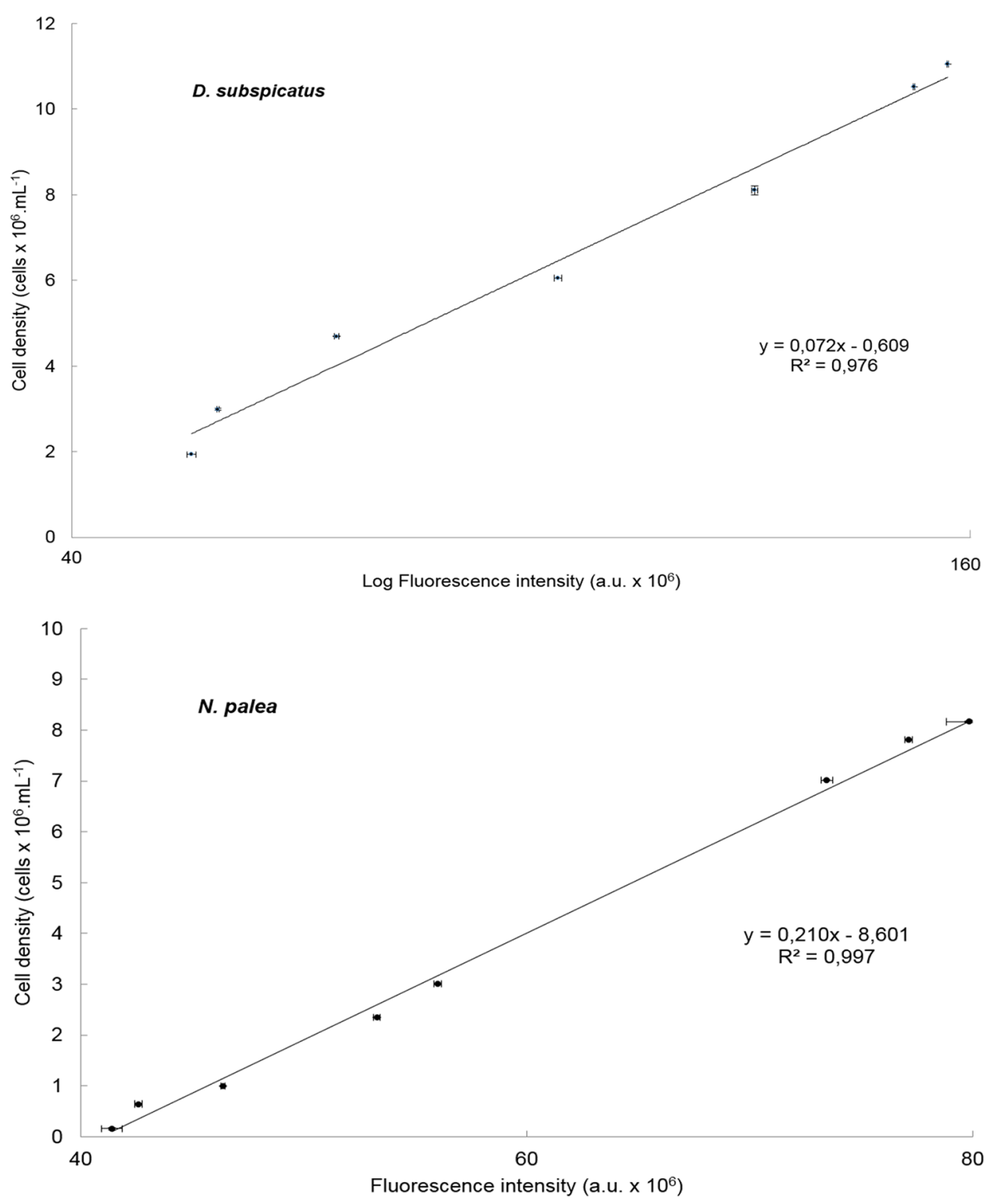

Fig. 1. Relationship between fluorescence intensity and cell density after $96 \mathrm{~h}$ of growth of the green alga $D$. subspicatus and the diatom N. palea. Each determination was carried out in triplicates. Error bars, SD.

situations in which IODO and BE concentration do not covary. Microalgae were grown for $96 \mathrm{~h}$ in $200 \mu \mathrm{l} \mathrm{COMBO}$ medium in 96-well polystyrene transparent microplates with low evaporation lid. The peripheral wells of the microplates were filled with $200 \mu \mathrm{l}$ of sterile medium to prevent the evaporation in the inner wells and help to control the lack of contamination. According to the linear range determined above (Fig. 1), we seeded 2000 cells per well (corresponding to an initial density of 10,000 cells $\mathrm{ml}^{-1}$ ) to test the agrochemicals. Fluorescence intensity was measured to quantify the growth in each microplate well at the end of the exposure to the tested compounds. Triplicate wells of a culture were exposed to each of the nine concentrations of each compound (Tab. 1). Each control containing the solvent of the tested agrochemical(s) at the highest final concentration $(0.02 \%)$ was carried out in hexaplicates. The mean fluorescence of replicate wells filled with only growth medium was subtracted from the fluorescence measured in both control and treated wells. Each dose-response curve was fitted from one experiment in which triplicates wells of a culture were treated with an agrochemical, a mixture or a combination.

\subsection{Statistical analysis}

We verified that no significant difference across the triplicates of each sample was consistently observed in each experiment using the Kruskal-Wallis and the associated post-hoc tests. Each dose response was fitted with the model function of Brain-Cousens (Ritz et al., 2015), which take into account the eventual presence of a hormesis:

$$
f(x,(b, c, d, e))=c+(d-c+f x / 1+\exp (b(\log (x)
$$

$-\log (e))))$,

where $b$ denotes the steepness of the dose-response curve, $c$ and $d$ the lower and upper asymptotes or limits of the response 
Table 3. Inhibitory effect of the 11 agrochemicals and the mixtures/combinations tested on three species of microalgae. Brain-Cousens model was used for the calculation of the $50 \%$ inhibition concentration $\left(\mathrm{IC}_{50}\right)$ value in molarity for the 11 agrochemicals and as a fraction of the $\mathrm{RCV}$ for the mixtures and combinations, the associated determination coefficient $\left(R^{2}\right)$ and the standard deviation (SD). NI, IC 50 could not be determined within the concentration range. A letter indicates a significant difference between the mean values $($ ANOVA, $\operatorname{Pr}(>F)<0.05$; Tuckey HSD test, $P$. adj $<0.05)$ of the mixtures/combinations.

\begin{tabular}{|c|c|c|c|c|c|c|}
\hline & D. subspicatus & & N. palea & & N. pelliculosa & \\
\hline ACLO & NI & & NI & & NI & \\
\hline CLOM & NI & & NI & & NI & \\
\hline FENO & $14884 \pm 3564$ & 0.84 & NI & & NI & \\
\hline IMAZ & NI & & $\mathrm{NI}$ & & $\mathrm{NI}$ & \\
\hline META & $900 \pm 174$ & 0.99 & NI & & NI & \\
\hline SMET & NI & & NI & & NI & \\
\hline DEA & $30349 \pm 5041$ & 0.99 & $49855 \pm 218$ & 0.93 & NI & \\
\hline \multirow[t]{2}{*}{$\mathrm{BE}$} & $21946 \pm 1$ & 0.94 & NI & & $18913 \pm 733$ & 0.98 \\
\hline & $\mathrm{IC}_{50} \pm \mathrm{SD}$ (fraction of RCV) & & $\mathrm{IC}_{50} \pm \mathrm{SD}$ (fraction of $\mathrm{RCV}$ ) & & $\mathrm{IC}_{50} \pm \mathrm{SD}$ (fraction of $\mathrm{RCV}$ ) & \\
\hline $\mathrm{IODO}+\mathrm{BE} 1$ & $1.87 \pm 0.38$ & 0.98 & NT & & NT & \\
\hline $\mathrm{IODO}+\mathrm{BE} 2$ & $4.67^{\mathrm{c}} \pm 0.93$ & 0.93 & NT & & NT & \\
\hline
\end{tabular}

and $e$ the effective dose ED50. The lower limit $c$ was set to 0 to fit the dose response of ATRA and FENO and the combination $\mathrm{IODO}+\mathrm{BE} 2$. The fit of the dose response of this combination was the best that could be obtained after testing the other models presented in Ritz et al. (2015).

$\mathrm{IC}_{50}$ and standard deviation calculation were performed using the Brain-Cousens model of the $d r c$ package (Ritz et al., 2015) of the $\mathrm{R}$ software ( $\mathrm{R}$ Core Team, 2014). One-way ANOVA analyses followed by the Tukey-Kramer Multiple Comparisons Test to compare the dose response of IODO to the three mixtures (MixAll; MixDs; MixDsw/oIODO) and the combinations $\mathrm{IODO}+\mathrm{BE}$ at $96 \mathrm{~h}$. Comparison of IC50s was performed on three values obtained from the model (IC50, IC50 + SD and IC50-SD). One-way ANOVA postulates (normality and homoscedasticity) were verified by ShapiroWilk test and Bartlett test.

\section{Results}

\subsection{Validation of the method}

The green alga grew 2.3-fold faster than $N$. palea and 1.8-fold faster than $N$. pelliculosa in the non-agitated microplates. Linear responses between cell density and either fluorescence intensity or log-transformed fluorescence intensity were observed with the diatoms (N. palea, $R^{2}=0.997$ and $N$. pelliculosa, $R^{2}=0.914$ ) and the green alga $D$. subspicatus $\left(R^{2}=0.983\right)$, respectively (Fig. 1 and Online Fig. 2 for N. pelliculosa). This response was observed within a range of $0.16-8.2$ (N. palea) or 0.15-10 (N. pelliculosa) $10 \times 10^{6}$ and $1.9-11 \times 10^{6}$ cells $\mathrm{ml}^{-1}$ for the diatoms and the green alga, respectively. Within the observed ranges of cell density, the three species could be grown for up to at least $144 \mathrm{~h}$ without reaching the highest cell number values.

The linear ranges of growth corresponded to an initial seeding of 5000-50,000 cells $\mathrm{ml}^{-1}$ of each species and the microplate wells of the growth inhibition assay were seeded with 10,000 cells $\mathrm{ml}^{-1}$. Analysis of the results obtained with the microplate assay revealed that no significant difference across the replicates $(0.11<P<0.84)$ was consistently observed using Kruskal-Wallis tests, indicating that, overall, the replication sampling was correctly processed.

\subsection{Effects of the agrochemicals tested singly}

Five $\mathrm{IC}_{50}$ values (ATRA, DEA, FENO, IODO and META) could be determined for D. subspicatus, two (ATRA and DEA) for $N$. palea and one (BE) for N. pelliculosa (Tab. 3). N. palea was slightly less sensitive $(P=0.05)$ than $D$. subspicatus to ATRA and DEA. It is worth noting that the diatom $N$. palea, but not $N$. pelliculosa, was sensitive to the photosystem II inhibitors ATRA and DEA. On the green microalga, IODO showed the highest growth inhibition (Tab. 3 and Fig. 2A/ Online Fig. 3A). It is worth noting that $29 \%$ of cells were able to grow in the presence of increased concentrations of IODO up to 10 -fold $\mathrm{RCV}$. The $\mathrm{IC}_{50}$ of IODO was not significantly different from that of META and ATRA $(P=0.91$ and 0.89 , respectively) and significantly different from that of FENO and DEA $(P<0.001)$.

Maximum growth stimulation of $10-43 \%$ was observed between 0.32 and 5.66-fold RCV, depending on species and compound (Online Tab.2). Growth stimulation was most frequently observed with $N$. palea. We determined the hormesis evidence category whenever possible 

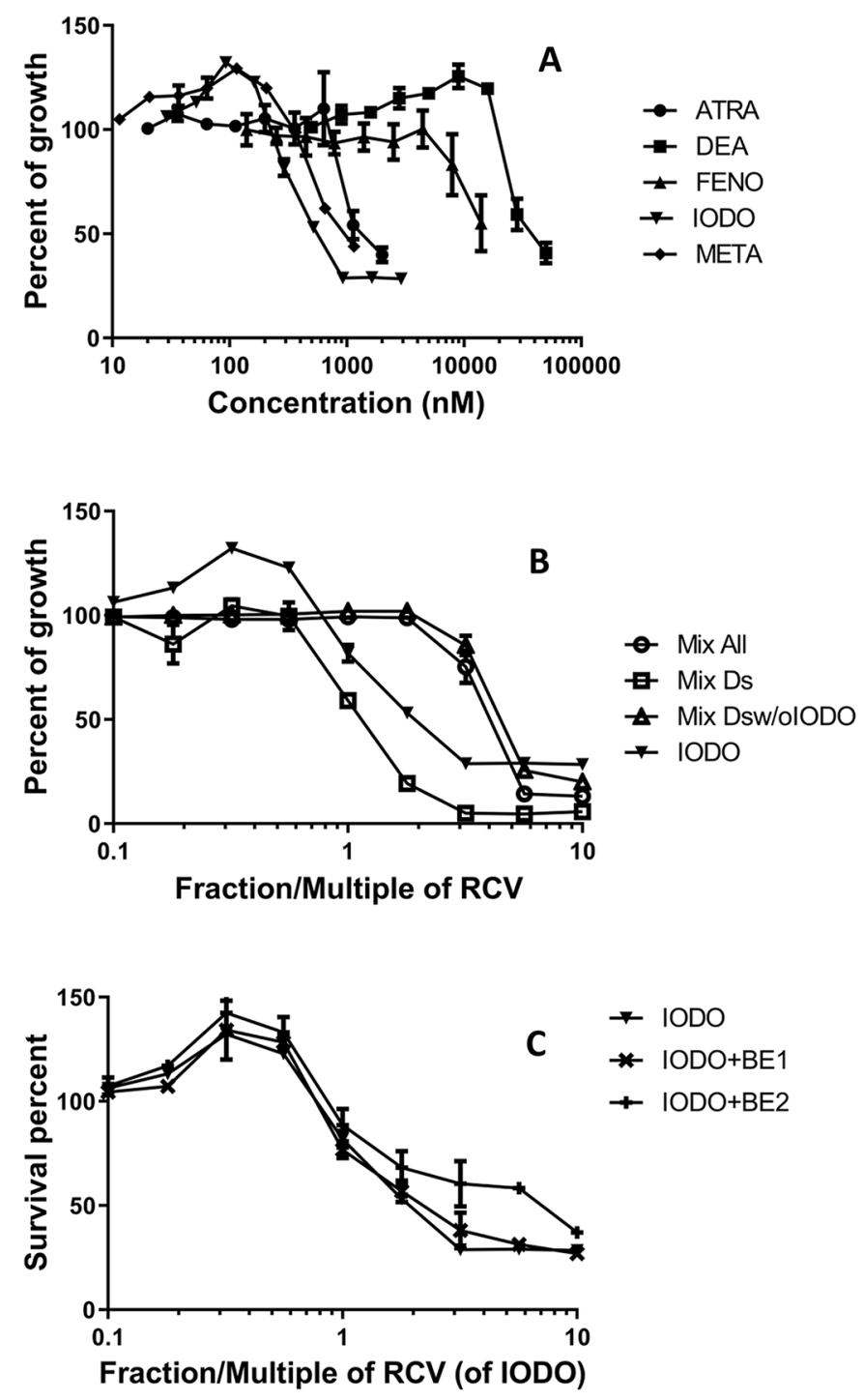

Fig. 2. Dose response of $D$. subspicatus to the agrochemicals after $96 \mathrm{~h}$ of growth. (A) The five active compounds. (B) The mixtures containing IODO. (C) The combinations of IODO and BE. Concentration values corresponding to each fraction of the RCV are those attributed to each agrochemical in Tables 1 and 2. Error bars, SEM.

(Online Tab.2) using the set of criteria awarded by Calabrese and Blain (2011) with assigned numerical values based on the quality of the study design, response magnitude, statistical analysis and reproducibility of the response.

\subsection{Effects of agrochemical mixtures}

As shown by the analysis of the IC50s expressed in fraction of RCV, MixAll exhibited higher growth inhibition on the green alga $D$. subspicatus than the diatoms $N$. palea and $N$. pelliculosa (Tab. 3). On the green alga, MixDs was 3-fold more toxic than MixAll $(P<0.001$; Fig. 2B/Online Fig. 3B and Tab. 3). Removing IODO from the MixDs resulted in a 3.5 -fold loss of toxicity $(P<0.001)$, while the $\mathrm{IC}_{50}$ of MixDsw/ oIODO was not significantly different from that of MixAll $(P=0.25)$.

The combination of the herbicide IODO with the lowest concentration of the safener (BE1) did not modify the shape of the dose-response curve (Fig. 2C). On the contrary, the combination of the highest concentration BE2 with IODO increased significantly the relative growth of the green alga D. subspicatus to $61 \%$ compared to that of IODO at 5.66-fold $\mathrm{RCV}(\operatorname{Pr}(>F)=0.002, P . \operatorname{adj}=0.003)$. Using the fit of the Brain-Cousens model, the addition of the BE1 concentration to IODO did not significantly modify the $\mathrm{IC}_{50}$ of the herbicide (Tab. $3 ; P=0.94$; Fig. 2C/Online Fig. $3 \mathrm{C}$ ) whereas the addition of the $\mathrm{BE} 2$ concentration decreased its toxicity by a factor of $2.6(P<0.01$; Fig. 2 C) according to the fit of the Brain-Cousens model that does not completely fit the experimental points (Online Fig. 3C and Tab. 3).

A limited but significant stimulation was observed with the diatom N. pelliculosa exposed to MixDs and MixDsw/ oIODO. We recorded similar growth stimulation for IODO and its combination with the two BE concentrations (Online Tab. 2). 


\section{Discussion}

\subsection{Validation of the approach}

As photosynthetic organisms, green microalgae and diatoms share many characters similar to those present in plants and can thus be targeted by agrochemical compounds released in agriculture areas. We are currently studying a specific agriculture area within a ripisylve of the river Garonne. In this study, we set up a new method to first perform a component-interaction analysis (bottom-up approach, Feron et al., 1998; Groten et al., 2001) to evaluate the toxicity of the 11 agrochemicals released in this area. A wholemixture analysis (top-down approach, Groten et al., 2001) to determine the growth inhibition of aquatic field samples have been performed on the same microalgae (results to be published).

The agrochemical compounds were tested both singly and in mixtures by using an automated microplate assay that we validated. The microalgae were exposed to a range of nominal concentrations of agrochemicals in order to compare their $\mathrm{IC}_{50}$. Among the tested agrochemicals tested singly, we could determine an $\mathrm{IC}_{50}$ value for six of them. In the other cases, the growth inhibition did not reach more than $20 \%$ at the highest concentration applied to the microalgae, making it impossible to determine $\mathrm{IC}_{50}$ value. The maximum concentration that did not allow determining $\mathrm{IC}_{50}$ values may have been too low, in particular in diatoms that were less sensitive than the green alga. Hence, some of the differential sensitivities pointed out in this study are to be viewed in the light of this limitation. Finally, it is worth noting that the axenic microalgae were grown as plankton, a culture condition that most probably made them more sensitive to xenobiotics than in natural biofilm even for diatoms that grew as small aggregates adherent to the bottom of the wells.

\subsection{Effect of the agrochemicals tested singly}

The selected diatoms species were less sensitive to the tested agrochemicals than the green alga. These results are in agreement with the overall greater sensitivity of the green algae compared to the diatoms as reported in Tomlin (2009). The benthic diatoms $N$. palea and $N$. pelliculosa are primary producers in freshwater biofilms and produce extracellular polymeric substances (EPS) (Sutherland, 2001; Larras et al., 2013), whereas the green alga membrane is directly in contact with the extracellular compartment. These EPS are able to interact with xenobiotics and limit their penetration into the cell compartment (Flemming et al., 2009; Larras et al., 2012). In this line, Chalifour and Juneau (2011) showed that $N$. pelliculosa secretes more EPS than $N$. palea and is less sensitive to ATRA and DEA than this species. More generally, the greater tolerance of diatoms may also be related to the presence of fucoxanthin in plastids that would protect these organisms from ATRA, CLOM and ISOX that induce photooxidation (Müller et al., 2001; Pinto et al., 2003; Dayan and Zaccaro, 2012).

Besides the growth inhibition effects induced by the agrochemicals, we recorded six cases of high evidence of hormesis when agrochemicals were tested singly on the three species. No relation could be found between the class of compounds and/or the amount of secreted EPS and the occurrence of hormesis. Although regulatory agencies still exclude the use of hormetic effects in their risk assessment definition, information about hormetic dose responses could help to reexamine the process of ecological risk assessment (Agathokleous et al., 2018).

\subsection{Effect of mixtures in relation to the presence of the safener}

The results that we obtained with the three tested mixtures of active compounds on the green alga show that the toxicity of these mixtures was rather unpredictable by comparing their dose-response curves (Figs. 2A and 2B). Unexpectedly, the mix of the 11 agrochemicals (MixAll that included IODO) was less toxic than IODO, which was the most inhibitory molecule tested in this study.

Among the tested agrochemical, the safener BE was the only agrochemical with no reported herbicide effect. No report of any effect of BE on IODO metabolism through cytochrome $\mathrm{P}_{450}$ or glutathione- $S$-transferases (GST) induction (Davies and Caseley, 1999) was found so far. Besides, a halogen atom is present in IODO, as in SMET and ATRA to which BE is associated in agrochemical preparations. GSTs catalyze the nucleophilic addition of the sulfur of glutathione (GSH) to the position of the halogen atom in SMET and ATRA (Prade et al., 1998). The potential chemical reactivity of IODO with GSH prompted us to test the combination of IODO with two BE concentrations that had no effect on the growth of D. subspicatus. The highest BE2 concentration decreased the toxicity of IODO that can be evaluated at 50\% growth inhibition as a 2.6- to 4-fold attenuation. Compared to that observed for IODO, the dose response to this combination indicates that the growth inhibitory effect of IODO on the green alga is reduced at 5.66-fold RCV when associated with $\mathrm{BE}$, while the hormesis effect remained similar. It must be noted that the non-toxic BE2 concentration (3.18-fold RCV) remained constant over the concentration range of IODO. On the contrary, in the MixAll, in which the BE concentration increased up to its $\mathrm{IC}_{60}$ at a concentration of 10 -fold $\mathrm{RCV}$, the toxicity of IODO was completely removed (Fig. 2B). In this mixture, five other active compounds can form adducts with GSH (Ekler and Stephenson, 1989; Tal et al., 1993; Prade et al., 1998) and a loss of effect could also result of their conjugation to GSH through GSTs induction by BE.

As it could be expected from possible additivity and/or synergy between compounds of different mechanisms of action, the mixture of the five active compounds (MixDs, including IODO) was more toxic than IODO on the green alga (Tab. 3). Surprisingly, removing IODO made the toxicity of the MixDsw/ oIODO very similar to that of the four herbicides that compose this mixture. These results made IODO play a pivotal role in the differential toxicity of these mixtures. IODO inhibits the acetolactate synthase (ALS), an enzyme involved in the synthesis of the three proteinogenic branched-chain amino acids, and thus impairs protein synthesis. In this line, imazethapyr, which also inhibits ALS, targets several hundred proteins that are differentially expressed by Arabidopsis thaliana under treatment with this herbicide (Qian et al., 2015). The mechanism(s) involved in the 
differential toxicity of MixDs and MixDsw/oIODO remain(s) to be determined.

\section{Conclusion}

We performed a component-interaction analysis of the growth inhibition of a green alga by 11 agrochemicals using a method that allows a high gain of time saving. The effect of two mixtures could not be correctly predicted from the effect of the compounds tested singly. A safener that is associated in agrochemical preparations with an herbicide of the mixture appeared to be responsible for the decreased toxicity of the most active compound. A biochemical approach allowed partly disentangling the interaction between the 11 agrochemicals released by the farmers in an agriculture area. Feron et al. (1995a,b) proposed to select the 10 most risky chemicals from mixtures released by hazardous waste sites. As shown in this study, non-active compounds may decrease the toxicity of risky compounds but others may increase it. We would suggest to also examine the chemistry and mechanisms of action of the compounds that will not be tested because of their low toxicity. This would help to better evaluate the actual impact of these mixtures on the surrounding ecosystems.

\section{Supplementary Material}

Supplementary material provided by the authors.

The Supplementary Material is available at https://www. limnology-journal.org/10.1051/limn/2019002/olm.

Acknowledgements. The authors are grateful to Jean-Louis Mergny (Inserm, Bordeaux) for his helpful collaboration in the first experiment and to David Riboul (EcoLab, Toulouse) for his help in the analysis of the chemical structure of herbicides to determine their ability to form adducts with glutathione. The authors also thank the two reviewers for their questions/ comments that allowed improving the article.

\section{References}

Abdullin SR, Bagmet VB. 2015. Experimental analysis for the possibility of heterotrophy in algae: the example of some strains from the Propashchaya Yama Cave. Russ J Ecol 46: 481-482.

Abu-Qare AW, Duncan HJ. 2002. Herbicide safeners: uses, limitations, metabolism, and mechanisms of action. Chemosphere 48: 965-974.

Agathokleous E, Kitao M, Calabrese EJ. 2018. Environmental hormesis and its fundamental biological basis: rewriting the history of toxicology. Environ Res 165: 274-278.

Anonymous. 2011. OECD Guidelines for the testing of chemicals, Section 2: Effects on biotic bystems. Test $N^{\circ} 201$ : Freshwater alga and cyanobacteria, growth inhibition test. Organ Econ Coop Dev $1-25$.

Baker LF, Mudge JF, Thompson DG, Houlahan JE, Kidd KA. 2016. The combined influence of two agricultural contaminants on natural communities of phytoplankton and zooplankton. Ecotoxicology 25: $1021-1032$.

Böger P. 2003. Mode of action for chloroacetamides and functionally related compounds. J Pestic Sci 28: 324-329.
Calabrese EJ, Blain RB. 2011. The hormesis database: the occurrence of hormetic dose responses in the toxicological literature. Regul Toxicol Pharmacol 61: 73-81.

Carder JP, Hoagland KD. 1998. Combined effects of alachlor and atrazine on benthic algal communities in artificial streams. Environ Toxicol Chem 17: 1415-1420.

Carvalho RN, Arukwe A, Ait-Aissa S, Bado-Nilles A, Balzamo S, Baun A, Belkin S, Blaha L, Brion F, Conti D, Creusot N, Essig Y, Ferrero VEV, Flander-Putrle V, Fürhacker M, Grillari-Voglauer R, Hogstrand C, Jonas A, Kharlyndoh JB, Loos R, Lundebye AK, Modig C, Olsson PE, Pillai S, Polak N, Potalivo M, Sanchez W, Schifferli A, Schirmer K, Sforzini S, Stürzenbaum SR, Softeland L, Turk V, Viarengo A, Werner I, Yagur-Kroll S, Zounkova R, Lettieri T. 2014. Mixtures of chemical pollutants at European legislation safety concentrations: how safe are they? Toxicol Sci 141: 218-233.

Cavas T. 2011. In vivo genotoxicity evaluation of atrazine and atrazine-based herbicide on fish Carassius auratus using the micronucleus test and the comet assay. Food Chem Toxicol 49: 1431-1435.

Chalifour A, Juneau P. 2011. Temperature-dependent sensitivity of growth and photosynthesis of Scenedesmus obliquus, Navicula pelliculosa and two strains of Microcystis aeruginosa to the herbicide atrazine. Aquat Toxicol 103: 9-17.

Chèvre N, Loepfe C, Singer H, Stamm C, Fenner K, Escher BI. 2006. Including mixtures in the determination of water quality criteria for herbicides in surface water. Environ Sci Technol 40: 426-435.

Davies J, Caseley J. 1999. Herbicide safeners: a review. Pestic Sci 55: 1043-1058.

Dayan FE, Zaccaro ML. 2012. Chlorophyll fluorescence as a marker for herbicide mechanisms of action. Pestic Biochem Physiol 102: 189-197.

Debenest T, Silvestre J, Coste M, Delmas F, Pinelli E. 2008. Herbicide effects on freshwater benthic diatoms: induction of nucleus alterations and silica cell wall abnormalities. Aquat Toxicol 88: 88-94.

Debenest T, Silvestre J, Coste M, Delmas F, Pinelli E. 2009. A new cell primo-culture method for freshwater benthic diatom communities. J Appl Phycol 21: 65-73.

Debenest T, Silvestre J, Coste M, Pinelli E. 2010. Effects of pesticides on freshwater diatoms. Rev Environ Contam Toxicol 203: 87-103.

Devault DA, Merlina G, Lim P, Probst JL, Pinelli E. 2007. Multiresidues analysis of pre-emergence herbicides in fluvial sediments: application to the mid-Garonne River. J Environ Monit 9: 1009-1017.

Duke SO, Dayan FE. 2011. Modes of action of microbially produced phytotoxins. Toxins 3: 1038-1064.

Ekler Z, Stephenson GR. 1989. Physiological responses of maize and sorghum to four different safeners for metazachlor. Weed Res 29: 181-191.

Ferhatoglu Y, Barrett M. 2006. Studies of clomazone mode of action. Pestic Biochem Physiol 85: 7-14.

Feron VJ, Cassee FR, Groten JP. 1998. Toxicology of chemical mixtures: international perspective. Environ Health Perspect 106: 1281-1289.

Feron VJ, Groten JP, Jonker D, Cassee FR, van Bladeren PJ. 1995a. Toxicology of chemical mixtures: challenges for today and the future. Toxicology 105: 415-427.

Feron VJ, Woutersen RA, Arts JHE, Cassee FR, de Vrijer F, van Bladeren PJ. 1995b. Safety evaluation of the mixture of chemicals at a specific workplace: theoretical considerations and a suggested two-step procedure. Toxicol Lett 76: 47-55. 
Fleeger JW, Carman KR, Nisbet RM. 2003. Indirect effects of contaminants in aquatic ecosystems. Sci Total Environ 317: 207-233.

Flemming HC, Murthy PS, Venkatesan R, Cooksey K. 2009. Marine and industrial biofouling. University of Duisburg-Essen, Duisberg, $333 \mathrm{pp}$.

Ghosh M, Gaur JP. 1998. Current velocity and the establishment of stream algal periphyton communities. Aquat Bot 60: 1-10.

Gilliom RJ. 2007. Pesticides in U.S. streams and groundwater. Environ Sci Technol 41: 3409-3414.

Gonzalez-Rey M, Tapie N, Le Menach K, Dévier MH, Budzinski H, Bebianno MJ. 2015. Occurrence of pharmaceutical compounds and pesticides in aquatic systems. Mar Pollut Bull 96: 384-400.

Groten JP, Feron VJ, Suhnel J. 2001. Toxicology of simple and complex mixtures. Trends Pharmacol Sci 22: 316-322.

Halstead NT, Mcmahon TA, Johnson SA, Raffel TR, Romansic JM, Crumrine PW, Rohr JR. 2014. Community ecology theory predicts the effects of agrochemical mixtures on aquatic biodiversity and ecosystem properties. Ecol Lett 17: 932-941.

Hanazato T. 2001. Pesticide effects on freshwater zooplankton: an ecological perspective. Environ Pollut 112: 1-10.

Kilham SS, Kreeger DA, Lynn SG, Goulden CE, Herrera L. 1998. COMBO: a defined freshwater culture medium for algae and zooplankton. Hydrobiology 377: 147-159.

Larras F, Bouchez A, Rimet F, Montuelle B. 2012. Using bioassays and species sensitivity distributions to assess herbicide toxicity towards benthic diatoms. PLoS One 7: 1-9.

Larras F, Montuelle B, Bouchez A. 2013. Assessment of toxicity thresholds in aquatic environments: does benthic growth of diatoms affect their exposure and sensitivity to herbicides? Sci Total Environ 463-464: 469-477.

Lee L, David L, Prisbylla MP, Cromartie TH, Dagarin DP, Howard SW, Provan MW, Ellis MK, Fraser T, Mutter LC. 1997. The discovery and structural requirements of inhibitors of $p$-hydroxyphenylpyruvate dioxygenase. Weed Sci 45: 601-609.

Moisset S, Tiam SK, Feurtet-Mazel A, Morin S, Delmas F, Mazzella N, Gonzalez P. 2015. Genetic and physiological responses of three freshwater diatoms to realistic diuron exposures. Environ Sci Pollut Res 22: 4046-4055.

Müller P, Li X, Niyogi KK. 2001. Update on photosynthesis nonphotochemical quenching: a response to excess light energy. Plant Physiol 125: 1558-1566.

Nagai T, Taya K, Annoh H, Ishihara S. 2013. Application of a fluorometric microplate algal toxicity assay for riverine periphytic algal species. Ecotoxicol Environ Saf 94: 37-44.

Peschke K, Geburzi J, Heinz RK, Wurm K, Triebskorn R. 2014. Invertebrates as indicators for chemical stress in sewage-influenced stream systems: toxic and endocrine effects in gammarids and reactions at the community level in two tributaries of Lake Constance, Schussen, and Argen. Ecotoxicol Environ Saf 106: 115-125.
Pinto E, Sigaud-Kutner TCS, Leitão MAS, Okamoto OK, Morse D, Colepicolo P. 2003. Heavy metal-induced oxidative stress in algae. J Phycol 39: 1008-1018.

Polard T, Jean S, Gauthier L, Laplanche C, Merlina G, Sánchez-Pérez JM, Pinelli E. 2011. Mutagenic impact on fish of runoff events in agricultural areas in south-west France. Aquat Toxicol 101: $126-134$

Posthuma L, Suter GW, Traas TP. 2002. Species sensitivity distributions in ecotoxicology. Virginia Institute of Marine Science, Gloucester Point, Virginia, 583 pp.

Prade L, Huber R, Bieseler B. 1998. Structures of herbicides in complex with their detoxifying enzyme glutathione- $S$-transferase: explanations for the selectivity of the enzyme in plants. Structure 6 : 1445-1452.

Qian H, Lu H, Ding H, Lavoie M, Li Y, Liu W, Fu Z. 2015. Analyzing Arabidopsis thaliana root proteome provides insights into the molecular bases of enantioselective imazethapyr toxicity. Sci Rep 5: 11975.

R Core Team. 2014. R: a language and environment for statistical computing. R Foundation for Statistical Computing, Vienna, Austria.

Rimet F, Cauchie HM, Hoffmann L, Ector L. 2005. Response of diatom indices to simulated water quality improvements in a river. J Appl Phycol 17: 119-128.

Ritz C, Baty F, Streibig JC, Gerhard D. 2015. Dose-response analysis using R. PLoS One 10: e0146021.

Schulz R. 2001. Rainfall-induced sediment and pesticide input from orchards into the Lourens River, Western Cape, South Africa: importance of a single event. Water Res 35: 1869-1876.

Silva E, Daam MA, Cerejeira MJ. 2015. Predicting the aquatic risk of realistic pesticide mixtures to species assemblages in Portuguese river basins. J Environ Sci 31: 12-20.

Sjollema SB, Martínezgarcía G, Van Der Geest HG, Kraak MHS, Booij P, Vethaak AD, Admiraal W. 2014. Hazard and risk of herbicides for marine microalgae. Environ Pollut 187: 106-111.

Spalding RF, Snow DD. 1989. Stream levels of agrichemicals during a spring discharge event. Chemosphere 19: 1129-1140.

Stoemer EF, Smol JP. 1999. The diatoms: applications for the environmental and earth sciences. Nordic J Bot 19: 384 .

Sutherland I. 2001. The biofilm matrix: an immobilized but dynamic microbial environment. Trends Microbiol 9: 222-227.

Tal A, Romano ML, Stephenson GR, Schwan AL, Hall JC. 1993. Glutathione conjugation: a detoxification pathway for fenoxapropethyl in barley, crabgrass, oat, and wheat. Pestic Biochem Physiol 46: 190-199.

Tomlin CDS. 2009. The pesticide manual: a world compendium, British Crop Production Council, Hampshire, 1457 pp.

Weis JS, Smith G, Zhou T, Santiago-Bass C, Weis P. 2001. Effects of contaminants on behavior: biochemical mechanisms and ecological consequences. Bioscience 51: 209-217.

Cite this article as: Chamsi O, Pinelli E, Faucon B, Perrault A, Lacroix L, Sanchez-Perez J-M, Charcosset J-Y. 2019. Effects of herbicide mixtures on freshwater microalgae with the potential effect of a safener. Ann. Limnol. - Int. J. Lim. 55: 3 